University of Wollongong

Research Online

Faculty of Commerce - Papers (Archive)

Faculty of Business and Law

$1-1-2009$

\title{
Understanding behaviour to inform water supply management in developed nations - A review of literature, conceptual model and research agenda
}

Anna Hurlimann

University of Melbourne

Sara Dolnicar

University of Wollongong, s.dolnicar@uq.edu.au

Petra Meyer

University of Wollongong, pkm894@uow.edu.au

Follow this and additional works at: https://ro.uow.edu.au/commpapers

Part of the Business Commons, and the Social and Behavioral Sciences Commons

\section{Recommended Citation}

Hurlimann, Anna; Dolnicar, Sara; and Meyer, Petra: Understanding behaviour to inform water supply management in developed nations - A review of literature, conceptual model and research agenda 2009, 47-56.

https://ro.uow.edu.au/commpapers/665

Research Online is the open access institutional repository for the University of Wollongong. For further information contact the UOW Library: research-pubs@uow.edu.au 


\title{
Understanding behaviour to inform water supply management in developed nations - A review of literature, conceptual model and research agenda
}

\begin{abstract}
Water is a scarce resource in many parts of the developed world. Two solutions are possible to address water scarcity: conservation of existing resources, or the further production of water from new sources e.g. through recycling of wastewater or desalination of seawater. However, the main hurdle to implementation of many of these solutions is often viewed as a lack of public willingness to adopt these alternative water behaviours. Research in this area is therefore crucial. Yet, and possibly due to the interdisciplinary nature of such research, there is currently no comprehensive overview of what has been done before. This study fills this gap by (1) choosing a general consumer behaviour perspective as a starting point, (2) developing a conceptual model of research required in the area of water-related public acceptance studies, (3) identifying eight key water-related behaviours which require future research attention, and (4) reviewing which areas of the conceptual model have been investigated in the past by conducting an extensive literature review of water-related social science research. The review established that the majority of work which has been conducted is located at the cross-roads of personal characteristics and behavioural intentions. Significant gaps exist in relation to researching the adoption of a wide range of demand-side water behaviours. This indicates a dominance of supply-side solutions in social-research exploration. The review identifies a number of research needs including: the exploration of actual adoption of water-related behaviours (rather than behavioural intentions); and to widen the scope of water behaviour enquiry to include more demand-side solutions. Given the increasing scarcity of water in many areas of the world, addressing these identified gaps will be of significant importance. Thus our model informs the social-research agenda for water policy.
\end{abstract}

\section{Keywords}

inform, water, supply, management, developed, nations, review, literature, conceptual, model, understanding, research, behaviour, agenda

\section{Disciplines}

Business | Social and Behavioral Sciences

\section{Publication Details}

Hurlimann, A., Dolnicar, S. \& Meyer, P. (2009). Understanding behaviour to inform water supply management in developed nations - A review of literature, conceptual model and research agenda. Journal of Environmental Management, 91 (1), 47-56. 
Understanding behaviour to inform water supply management in developed nations - A Review of Literature, Conceptual Model and Research Agenda

\author{
Anna Hurlimann ${ }^{1}$ \\ Faculty of Architecture Building and Planning \\ The University of Melbourne \\ Parkville, Melbourne, VIC 3207 \\ Australia \\ anna.hurlimann@unimelb.edu.au \\ Ph: +61 383446976 \\ Fax: +61383445532
}

Sara Dolnicar and Petra Meyer

Marketing Research Innovation Centre

School of Management and Marketing

University of Wollongong

Northfields Ave, Wollongong, NSW 2522

Australia

sara_dolnicar@uow.edu.au

${ }^{1}$ Corresponding author 


\title{
Understanding behaviour to inform water supply management in developed nations - A Review of Literature, Conceptual Model and Research Agenda
}

\begin{abstract}
Water is a scarce resource in many parts of the developed world. Two solutions are possible to address water scarcity: conservation of existing resources, or the further production of water from new sources e.g. through recycling of wastewater or desalination of seawater. However, the main hurdle to implementation of many of these solutions is often viewed as a lack of public willingness to adopt these alternative water behaviours. Research in this area is therefore crucial. Yet, and possibly due to the interdisciplinary nature of such research, there is currently no comprehensive overview of what has been done before. This study fills this gap by (1) choosing a general consumer behaviour perspective as a starting point, (2) developing a conceptual model of research required in the area of water related public acceptance studies, (3) identifying eight key water-related behaviours which require future research attention, and (4) reviewing which areas of the conceptual model have been investigated in the past by conducting an extensive literature review of water-related social science research.

The review established that the majority of work which has been conducted is located at the crossroads of personal characteristics and behavioural intentions. Significant gaps exist in relation to researching the adoption of a wide range of demand-side water behaviours. This indicates a dominance of supply-side solutions in social research exploration. The review identifies a number of research needs including: the exploration of actual adoption of water-related behaviours (rather than behavioural intentions); and to widen the scope of water behaviour enquiry to include more demand-side solutions. Given the increasing scarcity of water in many areas of the world, addressing these identified gaps will be of significant importance. Thus our model informs the social-research agenda for water policy.
\end{abstract}

Keywords: water conservation, recycled water, desalination, alternative sources of water, consumer behaviour, attitudes, knowledge. 


\section{Introduction}

Water is a critical resource. It supports human life and culture, ecological functions and economic activities. However, in many developed nations the demand for water is increasing at rates which are outstripping traditional supply sources. This is leading to a crisis of water management in many locations which is acknowledged in various international declarations (United Nations 2001; 2003).

A wide range of solutions have been developed to manage shortfalls between water availability and demand. These solutions can be broadly categorized into two approaches: those based on increasing supply, and those based on decreasing demand. Supply-side solutions range from small-scale decentralized approaches which include water saving household appliances, informal re-use of water, rainwater tanks, and household level wastewater treatment systems. Such innovations are discussed by Allon and Sofoulis (2006). Larger scale centralised solutions include city-wide wastewater recycling systems and seawater desalination plants, both of which have been implemented in various locations around the world (see for example: Government of Western Australia 2003). While Australia has always been drought prone, only recently has there been a policy escalation to address this through augmentation of sources in various major urban centres. The use of alternative water sources is thus increasing across the country. In Australia the use of recycled water is increasing, and presently accounts for $4 \%$ of total consumption (Australian Bureau of Statistics 2006), thus there is increasing potential for research on actual use of these alternative water sources. Demand-side (decreasing demand) solutions include initiatives such as increasing efficiency of appliances and water use restrictions. In Australia such restrictions are frequently imposed on households, industry and farmers during periodic water shortages (Nancarrow et al. 2002). Restrictions are also common place in other countries, for example in China (Rattay et al. 2006).

Historical evidence suggests that community attitudes to these alternative sources are critical to their success. A major barrier to some of these management approaches has been a lack of community acceptance. This is particularly problematic for the supply of alternative water sources for drinking purposes, most notably recycled water (Hurlimann and McKay 2004). As such, an in-depth understanding of the mechanisms that lead people to be supportive of alternative water sources is critically important. The study of water-related consumer behaviour is essential to provide insight into 
community attitudes to alternative water sources and related water behaviours. Despite the importance of such research, very little work has been undertaken in this area. As will be demonstrated in this article, the work that has been undertaken concentrates on a very limited section of behavioural theory.

The aim of this paper is to develop a conceptual model which specifies the kind of knowledge required to increase our understanding of water-related human behaviour. We will then provide a comprehensive review of the current state of knowledge related to water behaviour based on the conceptual model developed. The review of water-related literature aimed at capturing every single social science publication dealing with issues of acceptance of water from augmented sources. To achieve this, all journals the titles of which include either "environment" or "water" have been searched. The identified articles were used to find additional work through reference lists. As such the paper provides a research agenda for social scientists in the field of community attitudes to alternative water sources and water-related behaviour. This work will inform public policy in countries facing water shortage.

The paper is structured as follows: first, a conceptual model of water-related consumer behaviour is developed. This conceptual model is based on consumer behaviour theory. Secondly, we identify eight key water-related behaviours which require future research attention. Thirdly, the conceptual model serves as the guiding structure for the review of current knowledge in the field. The final result of both these steps leads to a knowledge map which gives clear guidance as to where future research efforts should be directed. Throughout the paper we refer to "water-related consumer behaviour" as including both water conservation behaviour and use of water from non-traditional sources. By "traditional water sources" we refer to reticulated water that is provided by water authorities and that only contains cleaned freshwater from sources such as rivers and ground water. We use the term "nontraditional water sources" to contain the entire set of other possible water sources, such as recycled wastewater, desalinated water, grey water, and other sources of water. Please note that the context of this study is water management in contexts, developed nations, where water is a commodity. The set of challenges in developing nations is different and is not the focus of the present study. 


\section{A conceptual model}

A conceptual model of water-related consumer behaviour (Figure 1) was developed. The model was deliberately developed using general consumer behaviour theory rather than from empirical studies in the area of water-related social research. The disadvantage of developing a model based on previous work is the over-emphasise on areas of research where much work has been done. Our approach allows identification of areas in which knowledge is lacking.

The conceptual model consists of five layers. The first layer is a wide range of personal characteristics (e.g. demographics) and situational influences (e.g. environmental, water and locational characteristics). The second layer consists of objective knowledge, and the possible impact of water-related interventions (e.g. marketing campaigns). The third, fourth and fifth layers are based on the Theory of Planned Behaviour (Ajzen 1985). These are: actual behaviour (fifth layer), behavioural intentions (fourth layer), antecedents of behaviour (including attitudes, social norms and perceived behavioural control - the third layer). The model assumes that personal and situational factors affect water-related knowledge as well as attitudes, social norms and perceived behavioural control. These in turn affect the fourth layer of the model, behavioural intentions. These behavioural intentions may ultimately lead to water-related behaviour (the firth layer of the model), such as conservation or use of alternative water sources. The theoretical basis of this model is now discussed and further described.

\subsection{The effect of personal characteristics and environmental / location characteristics on}

\section{behaviour}

In consumer research, many factors including demographics, social class and prior experience have been studied in an attempt to account for individual differences in consumer responses to information (Capon and Burke 1980; Jacoby et al. 1978; Moore and Lehmann 1980). The theory of planned behaviour regards demographic, environmental, and personal characteristic as background variables that can influence behaviour indirectly through affecting behavioural, normative, and control beliefs (Ajzen and Manstead 2007). An overview of existing research into these factors is provided below.

\subsubsection{The effect of personal characteristics on behaviour}


A vast range of studies have concluded that personal characteristics influence consumer behaviour.

The role of demographic characteristics on behaviour has received significant research attention.

Zeithaml (1985) assumes that income has a strong impact on choice decisions. Demographic factors such as age and income are understood to play an important role as moderators of relationships between psychological and behavioural constructs (Darian 1987; McDonald 1994). Additionally, Mc Donald (1994) found buyer behaviour is influenced by opportunities and constraints associated with lifestyle characteristics (such as retirement).

More recent research regarding consumer behaviour has abandoned the exploration of demographic factors and shifted attention to psychological constructs (Homburg and Giering 2001). In many situations a customer's demographic characteristics both affect and reflect their psychological state, values and behaviour (e.g. Dickerson and Gentry 1983; Kalyanam and Putler 1997). Wandel and Bugge (1997) showed that people in the highest educated group were more likely to put priority on environmentally sound production of food. They found that reasons for buying food produced in an environmentally sound manner were different in different age groups. Dolnicar and Leisch (2008) concluded that segments concerning different levels of pro-environmental behaviour at the tourist destination were distinct segments of the population which differed in a range of personal characteristics, such as gender and age. Wandel and Bugge (1997) showed that women are more likely to prioritize environmental aspects in their quality evaluation of food and are more likely to buy these products than men. However, Homburg and Giering (2001) found less evidence for moderating effects for gender and involvement. The review indicates that personal characteristics such as age, income, gender, having children in a household play an important role in affecting behaviour. The effect differs depending on the behaviour in question.

\subsubsection{The effect of environmental / location characteristics on behaviour}

Country segmentation approaches have been used by numerous researchers (including: Helsen et al. 1993; Sethi 1971). However, the approach ignores important within-country heterogeneity among consumers (such as differences between metropolitan, regional and urban areas) and commonalities among consumers in different countries (Ter Hofstede et al. 2002). Some researchers propose "crossnational segmentation", which groups consumers in different countries based on their similarities in 
needs (Ter Hofstede et al. 1999; Yavas et al. 1992). Empirical support has been found for local similarities in cultural, attitudinal and behavioural patterns (Parker and Tavassoli 2000; Ronen and Shenkar 1985). Ter Hofstede et al. (2002) developed a model which identified geographic segments for consumer products. The model recognizes consumer behaviour within those segments may not be perfectly homogeneous.

The study of the effect of locational characteristics on behaviour is growing as a direct result of globalization. Hassan and Katsanis (1994) argue that world cities such as Paris, New York and Tokyo might have more in common with one another than with their neighbouring regions. It is argued that regions might not display spatial independence in consumer behaviour even with their similarity in physical landscape, e.g., climate, topography or natural resources (Gentry et al. 1988; Parker and Tavassoli 2000). Similarity is hypothesised to be displayed more through predominant value and lifestyle systems. Empirical support for regional variations in consumer behaviour is provided by various researchers (Gentry et al. 1988; Parker and Tavassoli 2000). Location differences have also been found for buying behaviour regarding food (Myrland et al. 2000; Wandel and Bugge 1997).

\subsection{The effect of knowledge and marketing interventions on behaviour}

The role of knowledge on consumer behaviour has been extensively studied by consumer researchers. Focal issues range from knowledge measurement and information search (Brucks 1985; Rao and Sieben 1992), to product judgments (Maheswaran et al. 1996), information processing (Alba and Hutchinson 1987; Bettman and Park 1980; Park et al. 1994) and choice (Mitchell and Dacin 1996). There is general agreement that knowledge is a multidimensional construct (Brucks 1985; Mitchell and Dacin 1996; Park et al. 1994), but a number of alternative conceptualizations of knowledge have been proposed. Anderson (1983) suggests that product knowledge consists of declarative knowledge (product information) and procedural knowledge (expertise). Some authors hypothesise that expertise increases with product experience/familiarity (Alba and Hutchinson 1987; Moorthy et al. 1997).

\subsubsection{Knowledge and Behaviour}

Subjective and objective knowledge have different effects on information processing and consumer behaviours (Aurier and Ngobo 1999; Flynn and Goldsmith 1999). Objective knowledge increases the 
number of attributes examined in a complex usage situation whereas subjective knowledge is

significantly related to the tendency to request opinions rather than attribute information (Brucks 1985). Prior knowledge has been found to encourage information search by making it easier to process new information (Johnson and Russo 1984; Punj and Staelin 1983). In the health domain human behaviour is at the centre of much research. Knowledge, such as knowing about a disease after being diagnosed with illness such as cancer or a heart disease, can prompt life style changes (Blanchard et al. 2003). For example, in a sample population Harnack et al. (1997) found that cancer prevention-related nutritional knowledge corresponded to cancer prevention related dietary behaviour. Petrovici and Ritson (2006) also show that knowledge about nutrition has a positive influence on dietary health preventive behaviour.

\subsubsection{The effect of marketing interventions on behaviour}

Marketing interventions potentially have a significant impact on behaviour. Fishbein and Ajzen (1975) found that exposure to marketing interventions influences a person's beliefs, which then mediate their attitude towards the product. Behavioural intention is formed as a consequence of this attitude formation. A popular marketing intervention in the field of social marketing is nutrition education campaigns. Several studies have examined the effect on behaviour and found that they have mixed success in shaping the consumer behaviour (Menon et al. 2002). Herrmann et al. (2002) observed different consumer behaviour in Germany when consumers reduced beef demand due to the mad cow disease crisis. However, such a decrease was not found in Bavaria due to the success of the Statefinanced generic promotion program, which stressed regional origin and quality control (Herrmann et al. 2002).

Scholderer and Grunert (2001) investigated the determinants of eating fish before and after an advertising campaign in Denmark. They found that before the campaign no significant relationship was found between behavioural intention and its hypothesized determinants. In the post-campaign period, the social norm from 'family' contributed significantly to the explanation of the intention to eat fish. Amongst other factors such as availability and meal preparation skills, the intention to buy fish showed a significant impact on consumption frequency before an advertising campaign. After the campaign, only the intention to buy fish was a significant determinant of consumption frequency. In 
sum, it can be concluded that the effect of marketing interventions on consumer behaviour in general and in the social marketing context is well established and consequently must be included in the conceptual model proposed for water-related behaviour.

\subsection{The effect of attitudes, social norms and perceived behavioural control on behaviour}

The Theory of Planned Behaviour (Ajzen 1985) is a further development of the Theory of Reasoned Action (Fishbein and Ajzen 1975). The theory provides a conceptual framework for understanding human behaviour. It hypothesises that behavioural intentions are a good predictor of human behaviour and are influenced by three factors: attitudes towards the behaviour, subjective norms and perceived behavioural control. In this theory an attitude towards behaviour is a favourable or unfavourable evaluation of the behaviour. Subjective norm is the perceived social pressure to perform or not to perform the behaviour. Perceived behavioural control is the perceived capability to perform the behaviour. Each of the factors further consists of two dimensions. Attitudes towards a behaviour consist of people's beliefs about the consequences of performing a behaviour and people's evaluations of these consequences. Social norms consist of the beliefs about expectations of other people regarding the behaviour and how much people want to comply with these expectations. Perceived behavioural control consists of people's assessment of factors which facilitate or stand in the way of performing a behaviour and their perception of the extent to which they do so.

There are a number of questions raised about the predictive validity of the theory of planned behaviour. Some researchers argue that attitudes can directly influence behaviour, regardless of behavioural intention or subjective norm (Albrecht and Carpenter 1976; Manstead et al. 1983). In a meta-analysis of eighty-eight attitude-behaviour studies Kraus (1995) found attitudes significantly and substantially predict future behaviour. However, the majority of studies investigating the relationship between attitudes and behaviour conclude that the direct correlations of attitudes and behaviour are not high (Bagozzi 1978; Bagozzi and Burnkraut 1979; Bruvold 1973; Schuman and Johnson 1976). This indicates that additional factors are required to achieve high predictive validity in behavioural models.

One factor that is not accounted for in the Theory of Planned Behaviour is the effort which is associated with the specific behaviour under study. Bagozzi et al. (1990) suggest that if the amount of 
effort required to perform a behaviour is high, intentions to act will strongly mediate the relationship between attitudes and behaviour. If the required effort is low, attitudes will predict behaviour directly. A number of authors have questioned the contribution of the construct of subjective norm in predicting specific human behaviours. They have mainly questioned the operationalisation of the construct, not the importance of social influence per se (Terry and Hogg 1996; Trafimow and Finlay 1996).

Despite the criticisms of the Theory of Planned Behaviour acknowledged here, the theory has been successfully used in attempts to provide a better understanding of diverse range of human behaviours (Armitage and Conner 2001; Hagger et al. 2002; Pullen et al. 2001). We therefore use the theory of planned behaviour as the central point of the conceptual model of water-related consumer behaviour.

\subsection{The relation between behavioural intentions and behaviour}

A critical issue remains that consumers do not always purchase products despite their stated intentions to do so. For example, in relation to green power (e.g. wind power) Truffer et al. (2001) found that twenty per cent of consumers state a willingness to pay between 10 per cent and 20 per cent more for green power products, yet actual adoption is less than 1 per cent. The discrepancies that can exist between individuals' stated and actual behaviour has been considered when developing this model. Meta-analytic reviews show that attitudes, subjective norms and perceived behavioural control together explain 40-50 per cent of the intentional variance (Bamberg 2002). In prospective studies intention and perceived behavioural control typically account for $20-40$ per cent of the behavioural variance (Bamberg 2002). Consequently approximately two-thirds of the behavioural variance is unaccounted for by intention and perceived behavioural control (Bamberg 2002). This raises serious doubts whether intention and perceived behaviour are the only direct determinants of behaviour (Bamberg 2002).

In their theory of reasoned action, Fishbein and Ajzen (1975) state that behaviour can be best predicted from a person's intention, or willingness, to perform the behaviour. The theory of planned behaviour proposed that perceived behavioural control emerges as an additional predictor of intentions and actual behaviour. The theory suggests that the level of intention shown by an individual is the best predictor of behaviour. Intention is influenced by internal and external control constructs and is seen as a 
function of an individual's attitude toward behaviour and any subjective norms. Intention is a cognitive representation of an individual's behavioural tendency (Faiers et al. 2007).

Recent research has found that other variables emerge as additional distinctive predictors of intentions, such as self-identity, that is the extent to which performing the behaviour is an important component of a person's self-concept (Sparks and Shepherd 1992; Theodorakis 1994). Similar evidence was found with donating blood - people are more likely to intend to give blood if donating blood was an important part of their self-identity (Charng et al. 1988). Terry et al. (1999) supported the idea of selfidentity and extended this to social-identity and group norms. Group norm was related to behavioural intentions, but only for participants who identified strongly with the group. Importantly, researchers have also found that measures relating to past behaviour significantly improve the prediction of later behaviour (Saba and Di Natale 1999; Saba et al. 2000).

Consistent results for the relationship between behavioural intention and behaviour are delivered by Scholderer and Grunert (2001) as well as Olsen (2001). The intention towards the behaviour showed a significant impact on consumption frequency and a positive relationship between them. Intentions typically explain between nineteen per cent and thirty-eight per cent of the variances in behaviour in prospective studies (Ajzen 1991; Armitage and Conner 2001; Sheeran and Orbell 1998). Some studies show high correlation between an individual's intention and behaviour (Shepherd 1990; Towler and Shepherd 1991/1992), whereas other studies show a lower correlation (Saba and Di Natale 1999). Similar studies in various fields support the large effect of intention on behaviour (Armitage and Conner 2001; Sheeran et al. 1999; Sheeran and Orbell 1998). Thus in the context of water-related behaviours it will be important to understand the relationship between behavioural intentions and actual behaviour.

Developed from the theory discussed in section two of this paper, the conceptual model of water conservation behaviour and acceptance of water from alternative sources is presented in Figure 1. There are many behaviours which could contribute positively to the management of water supply. The behaviours chosen for exploration in this study were informed by Australian water policy (State and National) analysis and water industry (Australian Water Association) newsletters and emails. The 
following eight water-related behaviours were chosen for inclusion in this study: 1) The use of water from an alternative source (non-traditional) for non-potable purposes (all uses except drinking), 2) Drinking water from an alternative source, 3) Relocate (residential location) due to a water situation (e.g. because of drought, or because recycled water is added to the supply system), 4) Water conservation, 5) Communication of water-related issues (e.g. talking to friends and family, writing a letter to a newspaper editor), 6) Water-related purchase (e.g. the purchase and installation of a rain water tank, or the installation of a swimming pool), 7) Joining a water interest group (such as 'Citizens against drinking sewerage'), 8) Water-related illegal behaviour (e.g. non-compliance with water use restrictions, stealing water, or tampering with water meters). These behaviours listed are both supply and demand side solutions.

The behaviours chosen for exploration, are in our view distinctly different from each other. We deliberately keep them separate because we assume that they will each have distinctly different decision making considerations by individuals. For example, one could argue that joining an interest group (behaviour 4) is also communicating about water (behaviour 5). Yet, we believe that joining an interest group is a much more actively involved behaviour which leads to a larger sacrifice in time and more social connections made in the context of water activism etc.

\section{Existing knowledge about water-related behaviours}

Through an extensive review of literature, this section of the paper aims to describe which areas of the conceptual model presented (Figure 1) have been studied in the past as applied to water-related behaviours (listed in section 2.4). This review will lead to insights about knowledge levels across the entire conceptual model, thus highlighting a future research agenda. While literature reviews have been conducted in the past (see for example: Dolnicar and Saunders 2006; Hartley 2001; Po et al. 2003; Po and Nancarrow 2004), they are limited with regards to predominantly focusing on recycled water and are not based on a conceptual framework as is this review.

3.1 The effect of personal characteristics and environmental / location characteristics on waterrelated behaviour 
Overwhelmingly the most comprehensively researched component of water-related behaviours is with people's willingness to use recycled water for various uses (see for example: Australian Research Centre for Water in Society 1999; Bruvold 1972; Bruvold et al. 1981; Dolnicar and Schäfer 2009; Hills et al. 2002; Hurlimann 2008; Lohman and Milliken 1985; Marks et al. 2006; Stone and Company Incorporated 1974). These studies have found that close to personal use of recycled water (such as drinking and showering) are less 'accepted' than uses such as garden watering or toilet flushing. A significant body of research has been conducted to examine the effect that personal characteristics have had on willingness to use recycled water. Less research has been conducted on the effect of locational characteristics on these behaviours. An overview of existing research in these areas is provided below.

\subsubsection{The effect of personal characteristics on water-related behaviour}

Extensive research has been undertaken exploring socio-demographic characteristics of water-related behaviour, particularly of those willing to use recycled water. In research conducted during the 1970s and 1980s, higher levels of income, occupation and education were the factors most frequently found to be associated with greater acceptance levels of recycled water (including: Baumann and Kasperson 1974; Stone and Company Incorporated 1974). The role gender plays in acceptance of recycled water use has also been well researched. Some studies have found being male is a strong predictor of acceptance of recycled water use (Marks 2004; Nancarrow et al. 2008). However, results regarding gender and age are less consistent. More recently studies have found that socio-demographic factors are not good predictors of acceptance (Hartley 2001; Marks 2004). Insignificant and inconsistent findings within and between studies are reported, and is further contributed to and discussed by Dolnicar and Schäfer (2009) for acceptance of both recycled water and desalinated water.

Less research has been conducted on the effect of personal characteristics for other water-related behaviours. In a study of public attitudes towards water conservation, Flack and Greenberg (1987) found that higher paid and better educated respondents were more inclined to install water-saving devices. Vernon-Gerstenfeld and Hart (1991) found that younger and more highly educated people were more willing to adopt dual pipe systems for delivery of recycled water for non-drinking purposes.

\subsubsection{The effect of environmental / locational characteristics on water-related behaviour}


A medium level of research has been conducted into the effect of environmental or locational characteristics on water-related behaviour. In a study regarding public attitudes toward water conservation in the United States of America (USA), Flack and Greenberg (1987) investigated the effect of restrictions to lawn watering, and attitudes to various pricing regimes for water (e.g. water metering and flat-rate customers). With regard to the effect of water use restrictions, they found that when compared to unrestricted water users, those that were subject to restrictions were more willing to make voluntary changes to their residential horticultural practices for the purposes of reducing water demand. With regard to pricing Flack and Greenberg (1987) found consumers preferred the pricing regime they were presently subjected to (e.g. flat rate customers preferred a flat rate). Also investigating the price of water but in Tunisia and Jordan, Madi et al. (2003) found that the price of water affected farming profitability and farmers' willingness to pay for reclaimed water in a particular context.

Other studies have researched attitudes to conservation with communities impacted by restrictions. However, they have not compared this with communities not subject to water use restrictions (Friend and Coutts 2006; Marks et al. 2008; Randolph and Troy 2007). Allon and Sofoulis (2006) conducted cultural research on domestic water use in Sydney Australia, a city which has been subject to water use restrictions. The authors found that while participants of the study were found to take personal measures to save water, they were "largely stuck within current socio-technological systems".

Nancarrow et al. (2002) investigated community attitudes to water restrictions in Perth, Australia. They found that despite the introduction of water restrictions seventy-one per cent of respondents stated they did not change the time of day they watered their garden and lawn, and forty-seven per cent stated they did not change the length of time they watered. Frequency of garden watering was high with fifteen per cent of respondents reportedly watering their garden everyday, thirty-two per cent every second day, and forty-three per cent two to three times a week. The high use of water still evident by respondents could be explained by the fact that in total, thirty-five per cent of respondents owned or shared a bore, the use of which is not subject to water use restrictions. Despite restrictions to water use, seventy-nine per cent of respondents said that their lifestyles had not been affected by restrictions. 


\subsection{The effect of knowledge and marketing interventions on water-related behaviour}

A number of studies have investigated community knowledge of water-related issues in conjunction with behavioural studies. However, few have researched the effect knowledge, or marketing interventions have on actual behaviour. A review of the limited studies undertaken is provided below.

\subsubsection{The effect of knowledge on water-related behaviour}

Numerous studies of both a theoretical and empirical nature have investigated determinants of support for household water conservation. Watkins (1974) developed a water concern scale including measured attitudes to water. Dziegielewski (1994) involved belief in the seriousness of water shortage, knowledge of the potential savings, and the perception that conservation measures are equitable. These were found to be important determinants for support of household water conservation in predicting both per capita water consumption and adoption of water conservation behaviours. Bruvold (1979) focused on two variables 1) perceived seriousness of the drought, and 2) belief that conservation measures should be practiced in the long-term. Cameron and Wright (1990) added to this perceived benefit, attitude towards conservation and information possession.

In relation to recycled water use, Baumann (1983) found willingness to use was dependent upon the intended use of recycled water (e.g. personal versus non-personal use) and to knowledge concerning recycled water. In a study of farmers' attitudes to recycled water in Greece, Tsagarakis and Georgantzis (2003) found that small-scale farmers exhibit a positive attitude to the use of recycled water. They also found that willingness to use recycled water may increase with the availability of information regarding the effects of its use on private and social wellbeing. Other studies have also found that knowledge about recycled water (process, safety, benefits etc) influences willingness to use recycled water (including: Flack and Greenberg 1987; Hurlimann and McKay 2004; Jeffrey and Jefferson 2003; Lohman and Milliken 1985; Roseth 2008).

\subsubsection{The effect of marketing interventions on water-related behaviour}

The impact of marketing interventions on water-related behaviour has been researched to a limited extent. Interventions could include activities such as: public information campaigns (through various 
distribution methods including brochures, and the media), public policy (for example water use restrictions), marketing campaigns and demonstration projects (e.g. publicly accessible recycled water projects). Gibson and Apostolidis (2001) held a workshop during the initial phase of the Queensland (Australia) Water Recycling Strategy. A result of this workshop was the determination that a high priority must be given to the demonstration of recycling practices not being utilised in the State. Baumann (1983) conducted a literature review of recycled water research and established that there was a need for proper education, and exposure to recycled water to get the support of the public.

A number of recycled water demonstration plants have been built in Australia (Chapman 2006; Friend and Coutts 2006). While these demonstration plants have been built and documented, limited research has been conducted to assess how these demonstration plants have impacted the behaviour of individuals. The UK demonstration project 'The Watercycle project at the Millennium Dome' was one of the largest in-building recycling schemes in Europe, with 6 million visitors in 2000 (Hills et al. 2002). An investigation of visitor perceptions of recycled water was conducted. Surveys of 1,055 visitors to the Millennium Dome were conducted in relation to their water recycling and conservation initiatives. Results indicate that education, information and exposure to recycled water systems further increases users' acceptance of the concepts (Hills et al. 2002). The literature review conducted here reveals there is a lack of demonstration projects for other alternative sources of water, and limited research into the impact of these demonstration projects on actual behaviour.

Lohman and Milliken (1985) conducted a study in Denver, USA which measured the degree of public awareness about potable wastewater reuse. The authors analysed the effect of information/education measures on public understanding and acceptance of potable wastewater reuse. Analysis revealed that a prerequisite to positive change in attitude is an individual's faith in the water supply agency. Following that, reading material should be supplemented by the visual experience of a plant tour (actual or perhaps a filmed simulation) to achieve public interest and understanding of the reuse concept.

Water use restrictions are one example of a policy intervention by governments. Randolph and Troy (2007) investigated stated water use behaviour of 2179 Sydney households during periods of water use 
restrictions. They found that ninety percent of respondents stated they had in some way reduced their water use. Further research is required to explore actual behaviour change resulting from restrictions and other policy interventions. Various authors have discussed the effect media campaigns can have on people's attitudes to alternative water sources (Allon and Sofoulis 2006; Coutts 2006; Dishman et al. 1989; Friend and Coutts 2006; Marks et al. 2008; Po et al. 2003). However, none of these studies have measured the effect those campaigns have had on actual water use behaviour.

\subsection{The effect of attitudes, social norms and perceived behavioural control in relation to water}

\section{behaviours}

The theory of planned behaviour (Ajzen 1985) has received some attention with regards to water behaviours. Clark and Finley (2007) conducted a large study using the theory of planned behaviour as a theoretical framework in evaluating determinants of intention to implement a set of specific water conservation behaviours among residents of Blagoevgrad in Bulgaria. A positive and significant correlation of the theory of planned behaviour variables were found with water conservation intention. Self-perceived knowledge of climate change was also significantly related to intention. The authors tested the effect of environmental attitudes and concern over future shortage of water on conservation. They found these variables to be significant but relatively weak determinants. Trumbo and $\mathrm{O}^{\prime}$ Keefe $(2001 ; 2005)$ tested the theory of planned behaviour to predict water conservation intention and behaviour in California-Nevada. In addition to attitudes, social norms and perceived behavioural control, they considered socio-demographics, environmental values and information effects. The result showed that their model accounted for 27 per cent of the variance in behavioural intention, with the core theory of planned behaviour variables making up 67 per cent of the total.

Lam (1999) used a modified theory of planned behaviour model. The model included perceived moral obligation and perceived water rights in addition to the core theory variables, to separately predict intention to behaviour. The theory explained 41 per cent of the variance in intention to reduce usage and 24 per cent of the variance in intention to install water-saving appliances. To predict reduced use, the inclusion of the additional variables was not significant in the intention to that behaviour. With the installation of appliances, the additional variables had a small but significant contribution to the intention to install. In more recent work in Taiwan. Lam (2006) attempted to predict people's intention 
to save water (through the installation of dual flush control to toilets). Lam found that the theory of planned behaviour alone is insufficient to understand people's intention to install dual-flush controllers in toilets, but that subjective effectivenss of alternative solutions is a good predictor for the intention. Lam's results suggest tjat water-conservation campaigns should poblicise not only the effectiveness but the advantages of efficient technologies over traditional means.

Nancarrow et al. (2008; see also Po et al. 2005) used the Theory of Planned behaviour to assess intention to drink recycled water or eat produce irrigated with recycled water. The researchers found that 'perceived behaviour control' was not significant, however subjective norms were. Attitude (the extent to which a person believes that supporting the recycled water scheme will deliver positive outcomes) had a significant impact on intended behaviour. Their model accounted for eighty-five per cent of the variance of intended behaviour for horticultural irrigation, and eighty-nine per cent for indirect potable reuse. A useful review of select psychology studies regarding water and energy conservation is provided by Seligman and Finegan (1990). The authors suggest that some factors that are successful in determining consumption for one resource are not necessarily important for another. They explain that resource behaviours vary along the dimensions of difficulty to conserve and how private or public the nature of the consumption activity is. Importantly they suggest that public consumption activities are susceptible to a variety of social influence pressures (social norms) wjere as private consumption behaviours are more likely to be affected by internalization processes.

Substantial research has also been conducted with regard to how various attitudes and beliefs affect water-related behaviours. The relationship between environmental attitudes and related specific beliefs, and between environmental attitudes and specific water behaviours have been found to be unimpressive (Bruvold 1972). Bruvold's (1973) results indicate that attitudes are better understood if a combinatorial index of several relevant beliefs, and a combinatorial index of several relevant behaviours are themselves jointly related to attitude. Hurlimann et al. (2008) found the following attitudes to promote acceptance of recycled water use: trust the water authority, perception of fairness in terms of price, belief they are being properly informed about the water, and belief that there is no risk. 
As discussed in section 3.1, overwhelmingly the most comprehensively research component of waterrelated behaviours is with people's willingness to use recycled water. Attitudes to recycled water use are thus well researched, while attitudes to desalinated water have received little academic attention. Dolnicar and Schäfer (2009) conducted a novel comparative study of knowledge, perceptions and acceptability of recycled water and desalinated water in Australia. They found that respondents discriminated between recycled and desalinated water. Respondents understood that recycled water is a more environmentally-friendly option than desalinated water, but that they have fewer reservations about quality of desalinated water. Dolnicar and Schäfer found that respondents discriminate according to water use. Respondents' stated likelihood of adoption for close to body uses (e.g. drinking and showering) was high for desalinated water when compared to lower contact uses such as irrigation and cleaning for which recycled water was ranked higher.

\subsection{The relationship between behavioural intentions and behaviour relating to water-related behaviours}

The majority of research conducted surrounding water-related behaviours has been on behavioural intentions. Scarce research has been conducted on actual water-related behaviour. In particular there is a lack of research relating to gauging actual attitudes to recycled water use and desalinated water use. Most research that has been undertaken with regards to these behaviours has been undertaken hypothetically, on communities who have not had actual experience with the water behaviours studied. With regards to recycled water use, studies have been conducted with communities using this resource for non potable purposes (Albrechtsen 2002; Hills et al. 2002; Hurlimann 2008; Marks 2008), but not with communities using recycled water for potable purposes. These studies have been insightful revealing actual experiences of recycled water use, and informing aesthetic quality improvements in these and other projects. The CSIRO in Australia conducted research on participants who believed they were eating products grown with various alternative water sources, however they were being deceived for the purpose of the study (Nancarrow et al. 2008; Po et al. 2005). There is a limited, but growing body of research conducted on attitudes to water use restrictions by communities subject to actual restrictions (for example: Allon and Sofoulis 2006). As discussed in section 2.4 of this paper, it is important to research actual water-related behaviour rather than hypothetical behaviour. 


\section{Knowledge gaps}

Using the literature reviewed in section three of this paper, the extent to which previous research has addressed the concepts in the conceptual model is presented in Figure 1. Four shades of grey are used to indicate the extent to which these concepts have been addressed in past research. As can be seen from this figure, the vast majority of work is located at the cross-roads of personal characteristics and behavioural intentions.

In summarizing the literature review conducted in section three of this paper, it appears that prior work aiming at understanding water conservation behaviour, as well as people's willingness to use water from alterative sources, has only covered a very limited range of areas. There is great potential to further understand these behaviours and behavioural intentions through additional investigation of water-related interventions, social norms and perceived behavioural control. Further work regarding the influence of water related knowledge and environmental / locational characteristics would also be beneficial.

Some water behaviours and behavioural intentions included in the model have been scarcely investigated (such as water-related illegal behaviour, relocation, joining a water interest group, and communication of water-related issues). These behaviours could make a significant contribution to water resource management. Further knowledge and research is required in order to understand and positively influence these behaviours. As discussed in section 2.4 of this paper there have been mixed results related to whether behavioural intention does predict actual behaviour. Thus, further research to address the identified gap in actual water-related behaviroural research would be beneficial.

\section{Insert Figure 1}

\section{Conclusions}

This paper has presented and justified a conceptual model of water conservation behaviour and acceptance of the use of water from alternative sources in developed nations. This model was purposefully developed from general consumer behaviour literature in order to identify knowledge gaps. The most significant aspects of a comprehensive review of literature in the direct area of water 
behaviour were then presented. This two step conceptual model and review process allowed the identification of areas in which knowledge is lacking and informed the development of a water behaviour knowledge map, unconstrained by previous direct research.

The review of water-related behavioural literature established that the majority of work is located at the cross-roads of personal characteristics and behavioural intentions. Significant gaps exist in relation to the exploration of the adoption of a wide range of demand-side water behaviours. This indicates the dominance of supply-side solutions in social research exploration. Significant gaps exit with regards to researching actual behaviours, with a dominance of behavioural intention research. The one actual behaviour that has been researched to some degree is water conservation. Through the review, the following research needs have been identified:

1) the exploration of actual adoption of water-related behaviours (rather than behavioural intention)

2) widen the scope of water behaviour enquiry to include other demand-side solutions

3) further explore the role social norms and perceived behavioural control have on behavioural intentions and actual behaviour

4) further explore the role that water-related interventions may have to positively influence water-related behaviours

5) further understand the effect environmental and locational characteristics have on waterrelated behaviour.

Given the increasing scarcity of water in many areas of the world, addressing these identified gaps will be of significant importance. Thus our model informs a social-research agenda for water policy.

\section{Acknowledgements}

This study was funded through Australian Research Council (ARC) Discovery Grant (DP0878338). The authors wish to thank: Tanya Livermore, Julie Hayes, Deepika Mathur and Sarah Oberklaid for their research assistance and Rob Hood for his assistance with producing Figure 1. 
Figure 1: Conceptual model and knowledge map for water- related behaviours

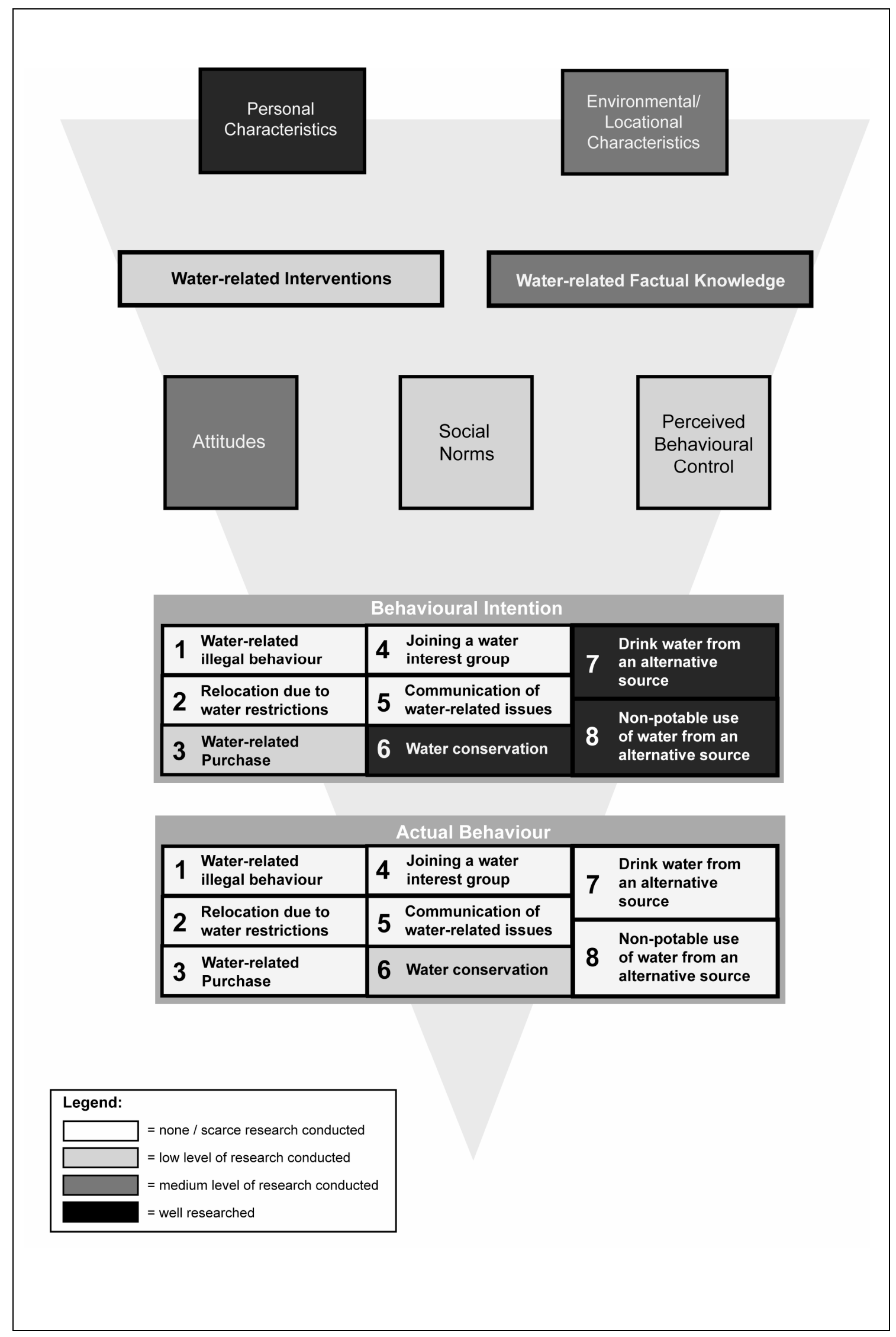




\section{References}

Ajzen, I., 1985. From intentions to actions: A theory of planned behaviour, in: Kuhl, J., and Beckman, J. (Eds.), Action-Control: From Cognition to Behaviour. Springer, Heidelberg, pp. 11-39.

Ajzen, I., 1991. The Theory of Planned Behaviour. Organisational Behavior and Human Decision Processes 50 (2), 197-211.

Ajzen, I., Manstead, A.S.R., 2007. Changing Health-related Behaviors: An Approach Based on the Theory of Planned Behavior, in: Van den Bos, K., Hewstone, M., de Wit, J., Schut, H., Stroebe, M., (Eds.), The Scope of Social Psychology: Theory and Applications. Psychology Press, New York, pp. 43-63.

Alba, J.W., Hutchinson, W.J., 1987. Dimensions of Consumer Expertise. Journal of Consumer Research 13 (4), 411-454.

Albrecht, S.L., Carpenter, K.E., 1976. Attitudes as Predictors of Behavior versus Behavior Intentions Convergence of Research Traditions. Sociometry 39 (1), 1-10.

Albrechtsen, H.J., 2002. Microbiological investigations of rainwater and graywater collected for toilet flushing. Water Science and Technology 46 (6-7), 311-316.

Allon, F., Sofoulis, Z., 2006. Everyday Water: cultures in transition. Australian Geographer 37 (1), 45 55.

Areni, C.S., Kiecker, P., Palan, K.M., 1998. Is it Better to Give Than to Receive? Exploring Gender Differences in the Meaning of Memorable Gifts. Psychology \& Marketing 15 (1), 81-109.

Armitage, C.J., Conner, M., 2001. Efficacy of the theory of planned behaviour: A meta-analytic review. British Journal of Social Psychology 40, 471-499.

Aurier, P., Ngobo, P.V., 1999. Assessment of Consumer Knowledge and Its Consequences: A MultiComponent Approach. Advances in Consumer Research 26.

Australian Bureau of Statistics, 2006. 4610.0: Water Account Australia 2004-2005. Australian Government, Canberra.

Australian Research Centre for Water in Society, 1999. Drinking Water Aesthetics: A Summary of an Integrated Methodology to Determine Community Preferences and Perceptions. CSIRO, Canberra.

Bagozzi, R.P., 1978. The Construct Validity of the Affective, Behavioral and Cognitive Components of Attitude by Analysis of Covariance Structures. Multivariate Behavioral Research 13, 9-31. 
Bagozzi, R.P., Burnkraut, R.E., 1979. Attitude Organization and the Attitude-Behavior Relationship. Journal of Personality and Social Psychology 37 (6), 913-929.

Bagozzi, R.P., Yi, Y., Baumgartner, J., 1990. The Level of Effort Required for Behaviour as a Moderator of the Attitude-Behaviour Relation. European Journal of Social Psychology 20, 2559.

Bamberg, S., 2002. Effects of Implementation Intentions on the Actual Performance of new Environmentally Friendly Behaviours - Results of two Field Experiments. Journal of Environmental Psychology 22, 399-411.

Baumann, D., 1983. Social Acceptance of Water Reuse. Applied Geography 3 (1), 79-84.

Baumann, D., Kasperson, R., 1974. Public Acceptance of Renovated Waste Water: Myth and Reality. Water Resources Research 10 (4), 667-674.

Bettman, J., Park, W.C., 1980. Effects of Prior Knowledge and Experience and Phase of the Choice Process on Consumer Decision Processes: A protocol Analysis. Journal of Consumer Research 7 (3), 234-248.

Blanchard, C.M., Denniston, M.M., Baker, F., Ainsworth, S., Courneya, K.S., Hann, D., Gesme, D., Reding, D., Flynn, T., Kennedy, J., 2003. Do Adult Cancer Survivors Change their Lifestyle Behaviors after a Cancer Diagnosis? American Journal of Health Behavior 27 (3), 246-256.

Brucks, M., 1985. The Effect of Product Class Knowledge on Information Search Behavior. Journal of Consumer Research 12 (1), 1-16.

Bruvold, W.H., 1972. Public Attitudes Toward Reuse of Reclaimed Water. University of California, Water Resources Centre, California.

Bruvold, W.H., 1973. Belief and Behavior as Determinants of Environmental Attitudes. Environment and Behavior 5, 202-218.

Bruvold, W.H., 1979. Residential Response to Urban Drought in Central California. Water Resources Research 15 (6), 1297-1304.

Bruvold, W.H., Olson, B.H., Rigby, M., 1981. Public Policy for the Use of Reclaimed Water. Environmental Management 5 (2), 95-107.

Cameron, T., Wright, M., 1990. Determinants of Household Water Conservation Retrofit Activity: A Discrete Choice Model Using Survey Data. Water Resources Research 26 (2), 179-188. 
Capon, N., Burke, M., 1980. Individual, Product Class, and Task-Related Factors in Consumer Information-Processing. Journal of Consumer Research 7 (3), 314-326.

Chapman, H., 2006. WRAMS, sustainable Water recycling. Desalination 188, 105-111.

Charng, H.-W., Piliavin, J.A., and Callero, P.L., 1988. Role Identity and Reasoned Action in the Prediction of Repeated Behavior. Social Psychology Quarterly 51 (4), 303-317.

Clark, W.A., Finley, J.C., 2007. Determinants of Water Conservation Intention in Blagoevgrad, Bulgaria. Society \& Natural Resources 20 (7), 613-627.

Coutts, S.S., 2006. A Recycled water strategy for regional urban communites. Desalination 188, 185194.

Darian, J.C., 1987. In-Home Shoppihg: Are There Consumer Segments. Journal of Retailing 63 (2), 163-186.

Dickerson, M.D., Gentry, J.W., 1983. Characteristics of Adopters and Non-adopters of Home Computers. Journal of Consumer Research 10 (2), 225-235.

Dishman, C., Sherrard, J., Rebbun, M., 1989. Gaining Public Support for Direct Potable Water Reuse. Journal of Professional Issues in Engineering 115 (2), 154.

Dodds, W.B., Monroe, K.B., Grewal, D., 1991. Effects of Price, Brand Store Information on Buyers' Product Evaluation. Journal of Marketing Research 28, 307-319.

Dolnicar, S., Leisch, F., 2008. Selective marketing for environmentally sustainable tourism. Tourism Management 29 (4), 672-680.

Dolnicar, S., Saunders, C., 2006. Recycled water for consumer markets - a marketing research review and agenda. Desalination 187 (1-3), 203-214.

Dolnicar, S., Schäfer, A.I., 2009. Desalinated versus recycled water: Public perceptions and profiles of the accepters. Journal of Environmental Management 90 (2), 888-900.

Dziegielewski, B., 1991. The Drought is Real: Designing a Successful Water Conservation Campaign, UNESCO/ORCAYT, Presented at Inaugural Ceremony International Seminar on Efficient Water Use, October 21-25 Montevideo, Uruguay. Viewed 10 May 2008 <http://www.unesco.org.uy/phi/libros/efficient_water/wbendzieg.html>

Faiers, A., Cook, M., Neame, C., 2007. Towards a Contemporary Approach for Understanding Consumer Behavior in the Context of Domestic Energy Use. Energy Policy 35, 4381-4390. 
Fishbein, M., Ajzen, I., 1975. Belief, Attitude, Intention, and Behavior: An Introduction to the theory and research. Addison-Wesley, Reading, MA.

Flack, E., Greenberg, J., 1987. Public Attitudes Toward Water Conservation. Journal of the American Water Works Association 79 (3), 46-51.

Flynn, L.R., Goldsmith, R.E., 1999. A Short, Reliable Measure of Subjective Knowledge. Journal of Business Research 46 (1), 57-66.

Friend, H.D., Coutts, S.S., 2006. Achieving sustainable recycled water initiatives through public participation. Desalination 187, 159-166.

Gentry, J.W., Tansuhaj, P., Manzer, L.L., John, J., 1988. Do Geographic Subcultures Vary Culturally? Advances in Consumer Research 15 (1), 411-417.

Gibson, H., Apostolidis, N., 2001. Demonstration, the Solution to Successful Community Acceptance of Water Recycling. Water Science and Technology 43 (10), 259-266.

Government of Western Australia, 2003. A State Water Strategy, for Western Australia. Perth: Government of Western Australia. Viewed on 21 September 2004 $<$ http://www.ourwaterfuture.com.au/Docs/State_Water_Strategy_complete.pdf $>$

Hagger, M.S., Chatzisarantis, N.L.D., Biddle, S.J.H., 2002. A meta-analytic review of the theories of reasoned action and planned behavior in physical activity: Predictive validity and the contribution of additional variables. Journal of Sport \& Exercise Psychology 24 (1), 3-32.

Harnack, L., Block, G., Subar, A., Lane, S., Brand, R., 1997. Association of Cancer Prevention Related Nutrition Knowledge, Beliefs, and Attitudes to Cancer Prevention Dietary Behaviour. Journal of the American Dietetic Association 97 (9), 957-965.

Hartley, T.W., 2001. Public Perception and Participation in Water Reuse: Literature Summary. Resolve Inc, Washington DC.

Hassan, S.S., Katsanis, L.P., 1994. Global Market Segmentation Strategies and Trends, in: Kaynak, E., Hassan, S.S. (Eds.), Globalization of Consumer Markets: Structures and Strategies. International Business Press, New York, pp. 47-61.

Helsen, K., Jedidi, K., DeSarbo, W.S., 1993. A New Approach to Country Segmentation Utilizing Multinational Diffusion Patterns. Journal of Marketing 57 (4), 60-71. 
Herrmann, R., Krischik-Bautz, S., Anders, S., 2002. Evaluating the Success of Generic Promotion for Beef: The Case of "Quality from Bavaria - Guaranteed Origin". Berichte ueber Landwirtschaft 80 (1), 53-84.

Hills, S., Birks, R., McKenzie, B., 2002. The Millennium Dome "Watercycle" experiment to evaluate water efficiency and customer perception at a recycling scheme for 6 million visitors. Water Science and Technology 46 (6-7), 233-240.

Homburg, C., Giering, A., 2001. Personal Characteristics as Moderators of the Relationship Between Customer Satisfaction and Loyalty - An Empirical Analysis. Psychology \& Marketing 18 (1), 43-66.

Hurlimann, A., 2008. Community Attitudes to Recycled Water Use and Urban Australian Case Study Part 2. Cooperative Research Centre for Water Quality and Treatment, Adelaide.

Hurlimann, A., McKay, J., 2004. Attitudes to Reclaimed Water for Domestic Use: Part 2. Trust. Water, Journal of the Australian Water Association 31 (5), 40-45.

Hurlimann, A., Hemphill, E., McKay, J., Geursen, G., 2008. Establishing Components of Community Satisfaction with Recycled Water Use through a Structural Equation Model. Journal of Environmental Management 88 (4), 1221-1232.

Jacoby, J., Chestnut, R.W., Fisher, W.A., 1978. Behavioral Process Approach to Information Acquisition in Nondurable Purchasing. Journal of Marketing Research 15 (4), 532-544.

Jeffrey, P., Jefferson, B., 2003. Public receptivity regarding "in-house" water recycling: results from a UK survey. Water Science and Technology: Water Supply 3 (3), 109-116.

Johnson, E.J., Russo, E.J., 1984. Product Familiarity and Learning New Information. Journal of Consumer Research 11 (1), 542-550.

Kalyanam, K., Putler, D.S., 1997. Incorporating Demographic Variables in Brand Choice Models: An Indivisible Alternative Framework. Marketing Science 16 (2), 166-181.

Kraus, S.J., 1995. Attitudes and the Prediction of Behaviour: A Meta-Analysis of the Empirical Literature. Personality and Social Psychology Bulletin 21 (1), 58-75.

Lam, S., 1999. Predicting Intentions to Conserve Water from the Theory of Planned Behavior, Perceived Moral Obligation, and Perceived Water Right. Journal of Applied Social Psychology 29 (5), 1058-1071. 
Lam, S. 2006. Predicting Intention to Save Water: Theory of Planned Behaviour, Response Efficacy, Vulnerability, and Perceived Efficiency of Alternative Solutions. Journal of Applied Social Psychology, 36 (11), 2803-2824.

Lohman, L., Milliken, J., 1985. Informational/Educational Approaches to Public Attitudes on Potable Reuse of Wastewater. U.S. Department of the Interior Geological Survey Reston, Virginia.

Madi, A., Braadbaart, O., Al-Sa'ed, R., Alaerts, G., 2003. Willingness of farmers to pay for reclaimed wastewater in Jordan and Tunisia. Water Science and Technology: Water Supply 3 (4), 115122.

Maheswaran, D., Sternthal, B., Guerhan, Z., 1996. Acquisition and Impact of Consumer Expertise. Journal of Consumer Psychology 5 (2), 115-133.

Manstead, A.S.R., Proffitt, C., Smart, J.L., 1983. Predicting and Understanding Mothers Infant-Feeding Intentions and Behavior - Testing the Theory of Reasoned Action. Journal of Personality and Social Psychology 44 (4), 657-671.

Marks, J., 2004. Advancing Community Acceptance of Reclaimed Water. Water Journal of the Australian Water Association 31 (5), 46-51.

Marks, J., Martin, B., Zadoroznyi, M., 2008. How Australians order acceptance of recycled water. Journal of Sociology 44 (1), 83-99.

Marks, J.S., Martin, B., Zadoroznyj, M., 2006. Acceptance of Water Recycling In Australia: National Baseline Data. Water Journal of the Australian Water Association 33 (2), 151-157.

McDonald, W.J., 1994. Time Use in Shopping: The Role of Personal Characteristics. Journal of Retailing 70 (4), 345-365.

Menon, G., Block, L.G., Ramanathan, S., 2002. We're at as much as we are Led to Believe: Effects of Message Cues on Judgements of Health Risks. Journal of Consumer Research 28 (4), 533-549.

Mitchell, A.A., Dacin, P.A., 1996. The Assessment of Alternative Measures of Consumer Expertise. Journal of Consumer Research 23 (3), 219-239.

Moore, W.L., Lehmann, D.R., 1980. Individual- Differences in Search Behaviour for a Nondurable Journal of Consumer Research 7 (3), 296-307.

Moorthy, S., Ratchford, B.T., Talukdar, D., 1997. Consumer Information Search Revisited: Theory and Empirical Analysis. Journal of Consumer Research 23 (4), 263-277. 
Myrland, O., Trondsen, T., Johnston, R.S., Lund, E., 2000. Determinants of Fish Consumption in Norway: Lifestyle, Revealed Preference, and Barriers to Consumption. Food Quality and Preference 11 (3), 169-188.

Nancarrow, B., Leviston, Z., Po, M., Porter, N., Tucker, D., 2008. What Drives Communities' Decisions and Behaviours in the Reuse of Wastewater. Water Science and Technology 57 (4), 485-491.

Nancarrow, B.E., Kaercher, J.D., Po, M., 2002. Community Attitudes to Water Restrictions Policies and Alternative Sources, A longitudinal analysis 1988-2002. CSIRO, Perth.

Olsen, S.O., 2001. Consumer involvement in seafood as family meals in Norway: an application of the expectancy-value approach. Appetite 36 (2), 173-186.

Park, W.C., Gardner, M.P., Thukral, V.K., 1988. Self-perceived Knowledge: Some Effects on Information Processing for a Choice Task. American Journal of Psychology 101 (3 (Fall)), 401-424.

Park, W.C., Mothersbaugh, D.L., Feick, L., 1994. Consumer Knowledge Assessment. Journal of Consumer Research 21 (1), 71-83.

Parker, P.M., Tavassoli, N.T., 2000. Homeostasis and Consumer Behavior Across Cultures. International Journal of Research in Marketing 17 (1), 33-53.

Petrovici, D.A., Ritson, C., 2006. Factors Influencing Consumer Dietary Health Preventative Behaviours. BMC Public Health 6, 1-12.

Po, M., Kaercher, J.D., Nancarrow, B.E., 2003. Literature Review of Factors Influencing Public Perceptions of Water Reuse. CSIRO Land and Water, Perth.

Po, M., and Nancarrow, B.E., 2004. Literature Review: Consumer Perceptions of the Use of Reclaimed Water for Horticultural Irrigation. CSIRO Land and Water, Perth.

Po, M., Nancarrow, B.E., Leviston, Z., Poter, N.B., Syme, G.J., Kaercher, J.D., 2005. Predicting Community Behaviour in Relation to Wastewater Reuse: What Drives Decisions to Accept of Reject? CSIRO, Perth.

Pullen, C., Walker, S.N., Fiandt, K., 2001. Determinants of Health-Promoting Lifestyle Behaviors in Rural Older Women. Family \& Community Health 24 (2), 49-72.

Punj, G.N., Staelin, R., 1983. A Model of Consumer Information Search Behaviour for New Automobiles. Journal of Consumer Research 9 (March), 366-380. 
Randolph, B., Troy, P., Water Restrictions as way of Moderating Demand. In Proceedings from the State of Australian Cities Conference, Adelaide, 28-30 November. The University of South Australia, p 535-545, CD ROM.

Rao, A., Sieben, W.A., 1992. The Effect of Prior Knowledge on price Acceptability and the Type of Information Examined. Journal of Consumer Research 19 (September), 256-270.

Rattay, A., Egger, G., Eybl, J., Planet Earth - Directions for Use. Presented at European Geoscience Union General Assembly, April 14-18, 2008, Vienna.

Ronen, S., Shenkar, O., 1985. Clustering Countries on Attitudinal Dimensions: A Review and Synthesis. Academy of Management Review 10 (3), 435-454.

Roseth, N., 2008. Community Views on Recycled Water - The Impact of Information. Cooperative Research Centre for Water Quality and Treatment, Adelaide.

Saba, A., Di Natale, R., 1999. A Study on the Mediating Role of Intention in the Impact of Habit and Attitude on Meat Consumption. Food Quality and Preference 10, 69-77.

Saba, A., Vassallo, M., Turrini, A., 2000. The Role of Attitudes, Intentions and Habit in Predicting Actual Consumption of Fat Containing Foods in Italy. European Journal of Clinical Nutrition $54,540-545$.

Scholderer, J., Grunert, K.G., 2001. Does Generic Advertising Work? A Systematic Evaluation of the Danish Campaign for Fresh Fish. Aquaculture Economics and Management 5 (2), 253-272.

Schuman, H., Johnson, M.P., 1976. Attitudes and Behavior. Annual Review of Sociology 2, 161-207.

Seligman, C., and Finegan, J. E. 1990. A Two-Factor Model of Energy and Water Conservation, in: Edwards, J., Tindale, R. S., Heath, L., and Posavac., E. J. (Eds.), Social Influence Processes and Prevention. Plenum Press, New York, pp. 279-299.

Sethi, S.P., 1971. Comparative Cluster Analysis for World Markets. Journal of Marketing Research 8 (3), 348-354.

Sheeran, P., Abraham, C., Orbell, S., 1999. Psychosocial Correlates of Heterosexual Condom Use: A Meta-Analysis. Psychological Bulletin 125 (1), 90-132.

Sheeran, P., Orbell, S., 1998. Do intentions predict condom use? Meta-analysis and examination of six moderator variables. The British Journal of Social Psychology 37, 231-250.

Shepherd, R., 1990. Overview of Factors Influencing Food Choice. British Nutrition Foundation Bulletin 15 (1), 12-30. 
Sparks, P., Shepherd, R., 1992. Self-identity and the Theory of Planned Behavior: Assessing the Role of Identification with "Green Consumerism". Social Psychology Quarterly 55 (4), 388-399.

Stone, R., Company Incorporated., 1974. Wastewater Reclamation: Socio-Economics, Technology, and Public Acceptance. U.S Department of the Interior, Los Angeles.

Ter Hofstede, F., Steenkamp, J.-B.E.M., Wedel, M., 1999. International Market Segmentation Based on Consumer-Product Relations. Journal of Marketing Research 36 (1), 1-17.

Ter Hofstede, F., Wedel, M., E.M., S.J.-B., 2002. Identifying Spatial Segments in International Markets. Marketing Science 21 (2, Spring), 160-177.

Terry, D.J., Hogg, M.A., 1996. Group norms and the attitude-behavior relationship: A role for group identification. Personality and Social Psychology Bulletin 22 (8), 776-793.

Terry, D.J., Hogg, M.A., White, K.M., 1999. The Theory of Planned Behavior: Self-identity, Social Identity and Group Norms. The British Journal of Social Psychology 38, 225-244.

Theodorakis, Y., 1994. Planned Behaviour, Attitude Strength, Role Identity, and the Prediction of Exercise Behaviour. The Sport Psychologist 8, 149-165.

Towler, G., Shepherd, R., 1991/1992. Modification of Fishbein and Ajzen's Theory of Reasoned Action to Predict Chip Consumption. Food Quality and Preference 3, 37-45.

Trafimow, D., Finlay, K.A., 1996. The Importance of Subjective Norms for a Minority of People: Between-subjects and Within-subjects Analyses. Personality and Social Psychology Bulletin $22(8), 820-828$.

Truffer, B., Markard, J., Wustenhagen, R., 2001. Eco-labelling of Electricity - Strategies and Tradeoffs in the Definition of Environmental Standards. Energy Policy 29 (11), 885-897.

Trumbo, C. W., O`Keefe, G.J., 2001. Intention to Conserve Water: Environmental Values, Planned Behavior, and Information Effects. A Comparison of three Communities Sharing a Watershed. Society \& Natural Resources 14 (10), 889-899.

Trumbo, C.W., O`Keefe, G.J., 2005. Intention to Conserve Water: Environmental Values, Reasoned Action, and Information Effects Across Time. Society \& Natural Resources 18 (6), 573-585.

Tsagarakis, K.P., Georgantzis, N., 2003. The role of information on farmers' willingness to use recycled water for irrigation. Water Science and Technology: Water Supply 3 (4), 105-113. 
United Nations, 2001. Resolution adopted by the General Assembly 55/196. International Year of Freshwater, 2003. United Nations. Viewed 20 May 2005, $<$ http://daccessdds.un.org/doc/UNDOC/GEN/NOO/571103.pdf?OpenElement $>$

United Nations. 2003. Resolution adopted by the General Assembly 58/217. International Decade for Action, Water for Life: 2005-2015. United Nations. Viewed 19 May 2005, $<$ http://www.unesco.org/water/water_celebrations/decades/water_for_life.pdf $>$

Vernon-Gerstenfeld, S., Hart, F.L., The Public's Acceptance of a Dual Potable Water Supply (Findings of a Statistical Survey). Presented at Conference on Environmetrics, Madison, Wisconsin.

Wandel, M., Bugge, A., 1997. Environmental Concern in Consumer Evaluation of Food Quality. Food Quality and Preference 8 (1), 19-26.

Watkins, G.A., 1974. Developing a "Water Concern" Scale. Journal of Enviornmental Education 5 (4), 54-58.

Yavas, U., Verhabe, B.J., Green, R.T., 1992. Global Consumer Segmentation Versus Local Market Orientation: Empirical Findings. Management International Review 32 (3), 265-272.

Zeithaml, V.A., 1985. The New Demographics and Market Fragmentation. Journal of Marketing 49 (3), 64-75. 